\title{
Patterns and predictors of analgesic use in pregnancy: a longitudinal drug utilization study with special focus on women with migraine
}

Gerd-Marie Eskerud Harris" ${ }^{1 *}$, Mollie Wood ${ }^{1}$, Malin Eberhard-Gran ${ }^{2,3}$, Christofer Lundqvist ${ }^{3}$ and Hedvig Nordeng ${ }^{1,2}$

\begin{abstract}
Background: Few studies have investigated the drug utilization patterns and factors predicting drug use in pregnant women with migraine. This longitudinal drug utilization study aimed to describe patterns of analgesic use in a sample of Norwegian pregnant women according to their migraine history, and to identify predictors for analgesic use among these women.

Methods: Pregnant women giving birth at Akershus University Hospital between 2008 and 2010 were recruited at ultrasound examination in gestational week 17. Data were collected by questionnaires in gestational weeks 17 and 32, and at 8 weeks postpartum, and linked to birth records. Women were grouped into four categories according to migraine history: no migraine history, previous migraine history, recent migraine history (within 1 year prior to pregnancy) and migraine in pregnancy. Patterns of use of analgesics were analyzed descriptively. Multivariable logistic regression was used to identify factors predicting analgesic use.

Results: Out of 1981 women, 5.0\% reported having migraine in pregnancy, 13.2\% had a recent history of migraine, $11.5 \%$ had a previous history of migraine, and $68.8 \%$ reported no history of migraine. Analgesic use declined during pregnancy. Many women switched from triptans and non-steroidal anti-inflammatory drugs to paracetamol, which constituted most of the analgesic use. Factors associated with analgesic use included recent migraine history (OR 1. $6,95 \% \mathrm{Cl} 1.2-2.2)$, more severe headache intensity (OR 1.3, 95\% Cl 1.3-1.4), smoking (OR 1.9, 95\% Cl 1.1-3.3) and multiparity (OR 1.4, 95\% Cl 1.1-1.7).

Conclusions: Women with migraine stop or switch medications during pregnancy. Analgesic use in pregnancy is affected by migraine characteristics and intensity, and also by socio-demographic factors. Clinicians should bear this in mind when giving advice on adequate management of migraine in pregnancy and safe analgesic use.
\end{abstract}

Keywords: Pregnancy, Drug utilization, Migraine, Analgesics, Predictors

\footnotetext{
* Correspondence: g.m.e.harris@farmasi.uio.no

${ }^{1}$ Pharmacoepidemiology \& Drug Safety Research Group, School of Pharmacy, Faculty of Mathematics and Natural Sciences, University of Oslo, P.O. Box. 1068, Blindern, 0316 Oslo, Norway

Full list of author information is available at the end of the article
} 


\section{Background}

Migraine affects approximately $20 \%$ of women of reproductive age [1]. Many women suffering from migraine experience an improvement in migraine symptoms during pregnancy, and about one third report complete remission $[2,3]$. However, pharmacotherapy is still necessary for many pregnant women with migraine. Analgesics, including triptans, non-steroidal anti-inflammatory drugs (NSAIDs), paracetamol and opioids, are commonly used to treat migraine, and paracetamol is recommended as first choice during pregnancy $[4,5]$.

Medical treatment of pregnant women is a challenge, and a balance between benefit for the mother and risk to the child must be maintained. The risk to the child is often overestimated, and will influence the decision to use a drug in pregnancy $[6,7]$. Socio-demographic characteristics and lifestyle factors may also impact medication use, but the results from previous studies are inconsistent [8-12]. Prevalence and patterns of medication use have been shown to vary between countries $[9,13]$. In a large multinational study conducted in 2011-2012, 81\% of all pregnant women used medications. Analgesics were the most common class of drugs, used by $56 \%$ of the women (38\% in first trimester, $44 \%$ in second, $36 \%$ in third) [8].

Few studies have investigated drug utilization patterns and factors predicting drug use in pregnant women with migraine. One population-based study found that $73 \%$ of pregnant women with migraine used anti-migraine drugs, mostly non-narcotic drugs (54\%) and triptans (25\%) [14]. This study also found a positive association between use of anti-migraine drugs and high body mass index, little sleep and being on sick-leave. Multiparous women were less likely to use triptans, but more likely to use other anti-migraine medications [14]. In another registry-based study, pregnant women using anti-migraine drugs (mainly sumatriptan) were older and more often primiparous than women not using such drugs [15]. A recently published cross-sectional study found no associations between anti-migraine medication use and migrainerelated, socio-demographic or lifestyle factors, when adjusting for migraine severity [16].

In order to provide optimal treatment and counselling to women with migraine who are pregnant or are planning to become pregnant, knowledge about drug utilization patterns and maternal factors affecting these patterns are necessary. This study aims to describe patterns of analgesic use in a sample of Norwegian pregnant women according to their migraine history, and to identify predictors for analgesic use among these women. Based on previous studies, we hypothesized that the drug utilization patterns would decrease in pregnancy and that severity of migraine would be more important than sociodemographic, lifestyle and other medical factors for use of analgesics among pregnant women.

\section{Methods}

\section{Study sample and design}

The current study uses data from the Akershus Birth Cohort Study (ABC study), which targeted all pregnant women scheduled to deliver at Akershus University Hospital (Ahus) in Norway. The hospital serves a population of approximately 400,000 individuals from both urban and rural surroundings, and had an average birth rate of 3500 births each year during the study period.

Pregnant women were recruited between November 2008 and April 2010 by a trained midwife at ultrasound examination in gestational week 17-20. This examination is offered to all pregnant women free of charge as part of the public antenatal care program in Norway. There were no exclusion criteria other than not being able to complete a questionnaire in Norwegian. Of the 4814 pregnant women invited to participate, 4623 women were included in the study (96.0\%).

Data were collected by self-completed questionnaires in gestational weeks $17(\mathrm{Q} 1)$ and $32(\mathrm{Q} 2)$, and at 8 weeks postpartum (Q3), and thereafter linked to the hospital birth records. The response rates were $81.0 \%$ (3744 of 4623), $81.1 \%$ (2931 of 3613) and $79.0 \%$ (2213 of 2801), respectively. For the current study, the final study sample consisted of 1981 women who completed all three questionnaires, representing $42.9 \%$ of those included. Women included in our study sample were older, less often smokers, more often married or cohabiting, had higher education and higher headache intensity, compared to those in the full cohort (Additional file 1: Table S1). An overview of inclusion, response rates and the study sample is presented in Fig. 1.

\section{Maternal characteristics}

An overview of the sources of the relevant variables describing maternal characteristics is presented in Fig. 2.

\section{Migraine characteristics}

Migraine was self-reported in the first and second questionnaires, which include specific questions about lifetime prevalence of migraine (Q1; "Have you ever had migraine?"), and migraine frequency in the past month (Q2; "How many days have you had migraine within the past month?"). This enabled us to group women into four mutually exclusive categories according to migraine pattern: no migraine history ("never had migraine"), previous history of migraine ("have had migraine, but not during the past year"), recent history of migraine (within 1 year prior to pregnancy) ("have had migraine during the past year"), and migraine in pregnancy (one or more days with migraine within the past month during the last part of pregnancy).

Headache intensity was measured in the first and second questionnaire by a numeric rating scale from 0 to 10 where 0 is no pain at all and 10 is the strongest 


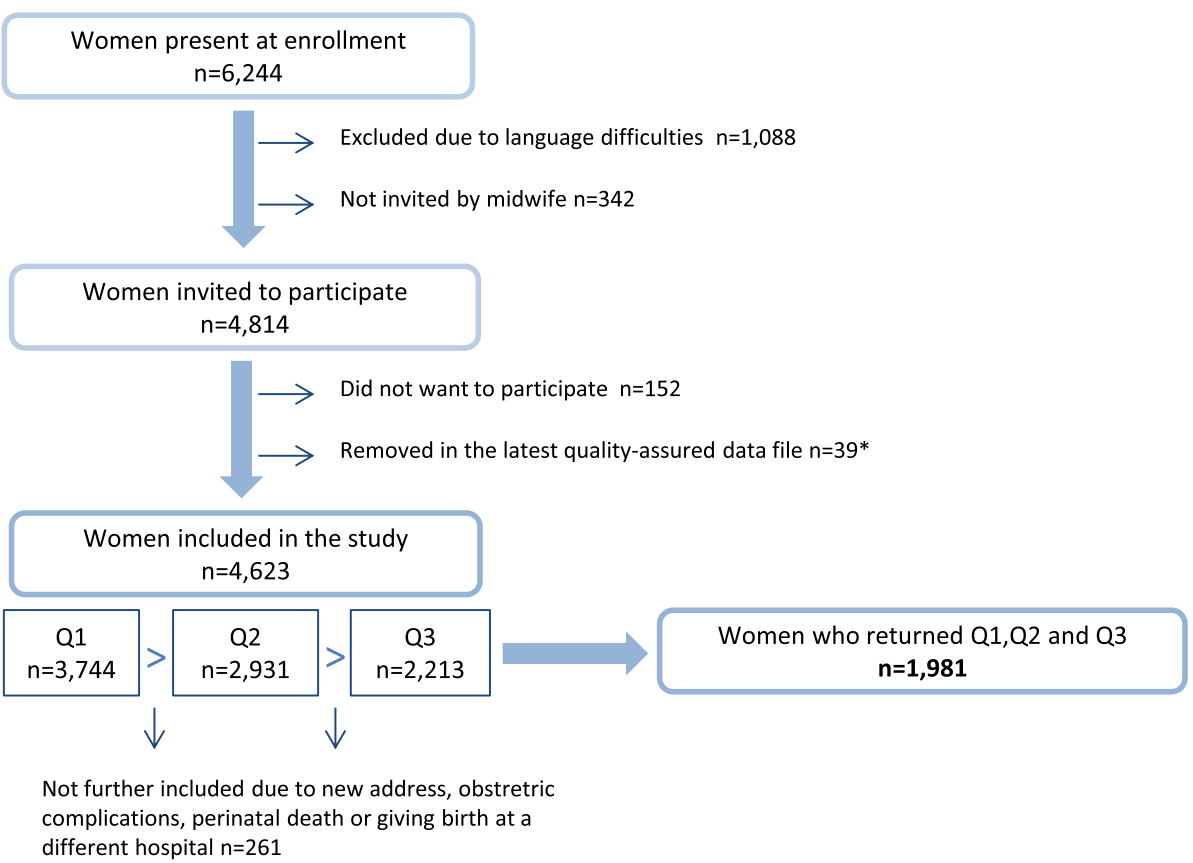

Fig. 1 The Akershus Birth Cohort: overview of inclusion, response rates and the study sample. *Note that the sample sizes may deviate somewhat from previous publications based on this data material due to small changes in the latest quality-assured data file released for research

pain imaginable, categorized as low (0-3), moderate (4-6) or high (7-10).

\section{Analgesic use}

Women were specifically asked about use of drugs within seven categories - drugs for headache, migraine, non-headache pain, insomnia, anxiety, depression and other psychotropic medications. For each medication group, the women could tick yes or no as to whether she used such a drug, and fill in the name of the medication. The three questionnaires cover different periods of use - four months before pregnancy and beginning of pregnancy until week $17(\mathrm{Q} 1)$, week 18 to $32(\mathrm{Q} 2)$, and the last part of pregnancy from week 33 forward (Q3).
Drug exposure was coded in groups based on the Anatomical Therapeutic Chemical (ATC) Classification System [17]. We defined use of analgesics as use of paracetamol (N02BE01), NSAIDs (M01A), triptans (N02CC) or opioids (N02A) reported as used for either headache or migraine. Variables were created for the pre-pregnancy period, pregnancy overall, and the time-specific periods in pregnancy covered by Q1, Q2 and Q3 - for analgesics overall and for the different substances.

\section{Socio-demographic characteristics, lifestyle factors and comorbidity}

Socio-demographic and lifestyle characteristics were categorized as presented in Table 1.

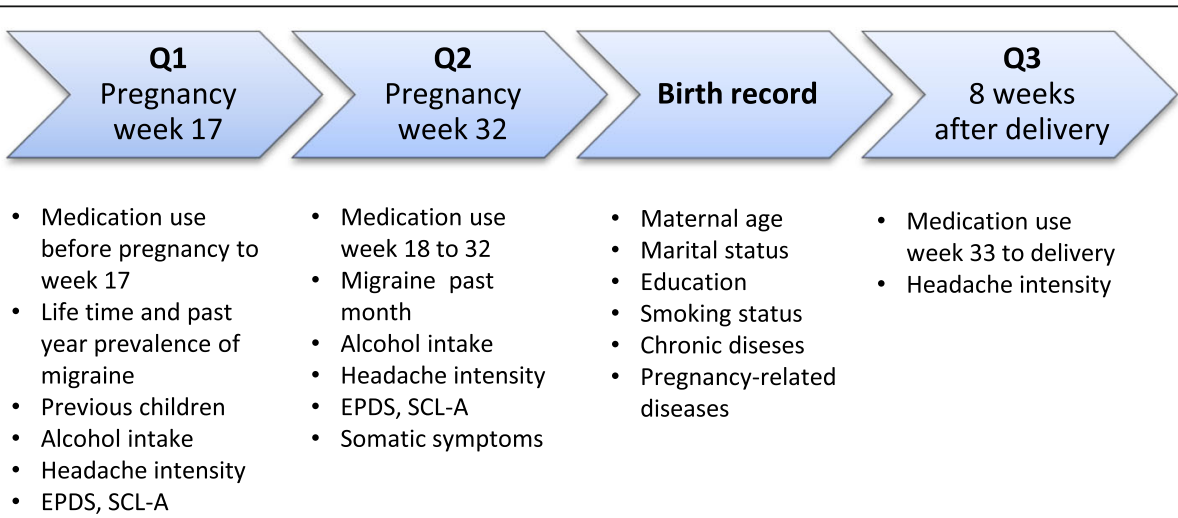

Fig. 2 The Akershus Birth Cohort: overview of the relevant variables measured in the questionnaires and birth record 
Table 1 Overview of maternal characteristics and analgesic use in pregnancy in the total study sample and in sub-samples according to migraine pattern

\begin{tabular}{|c|c|c|c|c|c|}
\hline & \multirow{2}{*}{$\begin{array}{l}\text { Study sample } \\
\text { Total number } \\
\text { of women }\end{array}$} & \multicolumn{4}{|c|}{$\underline{\text { Sub-samples according to migraine pattern }}$} \\
\hline & & $\begin{array}{l}\text { No history of } \\
\text { migraine }\end{array}$ & $\begin{array}{l}\text { Previous history } \\
\text { of migraine }\end{array}$ & $\begin{array}{l}\text { Recent history } \\
\text { of migraine }\end{array}$ & $\begin{array}{l}\text { Migraine in } \\
\text { pregnancy }\end{array}$ \\
\hline & $\begin{array}{l}n=1981 \\
n(\% \text { of } n)\end{array}$ & $\begin{array}{l}n=1362 \\
n(\% \text { of } n)\end{array}$ & $\begin{array}{l}n=227 \\
n(\% \text { of } n)\end{array}$ & $\begin{array}{l}n=262 \\
n(\% \text { of } n)\end{array}$ & $\begin{array}{l}n=100 \\
n(\% \text { of } n)\end{array}$ \\
\hline \multicolumn{6}{|l|}{ Maternal age at delivery } \\
\hline$<25$ & $165(8.3)$ & $119(8.7)$ & $12(5.3)$ & $16(6.1)$ & $15(15.0)$ \\
\hline $25-30$ & $588(29.7)$ & $403(29.6)$ & $64(28.2)$ & $79(30.2)$ & $29(29.0)$ \\
\hline $31-35$ & $768(38.8)$ & $529(38.8)$ & 95 (41.9) & $100(38.2)$ & $38(38.0)$ \\
\hline$>35$ & $446(22.5)$ & $303(22.2)$ & $56(24.7)$ & $62(23.7)$ & $17(17.0)$ \\
\hline \multicolumn{6}{|l|}{ Parity } \\
\hline First time mother & $988(49.9)$ & $669(49.1)$ & $102(44.9)$ & $148(56.5)$ & $53(53.0)$ \\
\hline$\geq 1$ previous child & $993(50.1)$ & $693(50.9)$ & $125(55.1)$ & $114(43.5)$ & $47(47.0)$ \\
\hline \multicolumn{6}{|l|}{ Marital status } \\
\hline Married/cohabiting & $1910(96.4)$ & $1318(96.8)$ & $222(97.8)$ & $246(93.9)$ & $94(94.0)$ \\
\hline Single/divorced/separated & $44(2.2)$ & $28(2.1)$ & $5(2.2)$ & $7(2.7)$ & $4(4.0)$ \\
\hline \multicolumn{6}{|l|}{ Education } \\
\hline College/university & $1294(65.3)$ & $905(66.4)$ & $146(64.3)$ & $160(61.1)$ & $61(61.0)$ \\
\hline Primary/secondary school & $606(30.6)$ & $406(29.8)$ & $69(30.4)$ & $86(32.8)$ & $37(37.0)$ \\
\hline \multicolumn{6}{|l|}{ Smoking at time of delivery } \\
\hline No & $1841(92.9)$ & $1280(94.0)$ & $211(93.0)$ & $235(89.7)$ & $87(87.0)$ \\
\hline Yes & $76(3.8)$ & $42(3.1)$ & $11(4.8)$ & $14(5.3)$ & $8(8.0)$ \\
\hline \multicolumn{6}{|l|}{ Alcohol in pregnancy } \\
\hline No & $1866(94.2)$ & $1282(94.1)$ & $210(92.5)$ & $255(97.3)$ & $93(93.0)$ \\
\hline Yes & $82(4.1)$ & $56(4.1)$ & $11(4.8)$ & $7(2.7)$ & $6(6.0)$ \\
\hline \multicolumn{6}{|c|}{ Symptoms of depression or anxiety in pregnancy } \\
\hline No & $1684(85.0)$ & $1184(86.9)$ & $192(84.6)$ & $218(83.2)$ & $68(68.0)$ \\
\hline Yes & $291(14.7)$ & $172(12.6)$ & $35(15.4)$ & $44(16.8)$ & $32(32.0)$ \\
\hline \multicolumn{6}{|l|}{ Chronic diseases } \\
\hline None & $831(41.9)$ & $590(43.3)$ & $92(40.5)$ & $102(38.9)$ & $34(34.0)$ \\
\hline 1 disease & $747(37.7)$ & $506(37.2)$ & $94(41.4)$ & $95(36.3)$ & $40(40.0)$ \\
\hline$\geq 2$ diseases & $392(19.8)$ & $260(19.1)$ & $41(18.1)$ & $61(23.3)$ & $25(25.0)$ \\
\hline \multicolumn{6}{|l|}{ Pregnancy related diseases } \\
\hline None & $1777(89.7)$ & $1221(89.6)$ & $212(93.4)$ & $229(87.4)$ & $87(87.0)$ \\
\hline$\geq 1$ disease & $191(9.6)$ & $134(9.8)$ & $15(6.6)$ & $29(11.1)$ & $11(11.0)$ \\
\hline \multicolumn{6}{|l|}{ Somatic symptoms } \\
\hline None & $182(9.2)$ & $139(10.2)$ & $20(8.8)$ & $20(7.6)$ & $1(1.0)$ \\
\hline 1-2 symptoms & $729(36.8)$ & $533(39.1)$ & $80(35.2)$ & $83(31.7)$ & $20(20.0)$ \\
\hline 3-4 symptoms & $658(33.2)$ & $430(31.6)$ & $84(37.0)$ & $93(35.5)$ & $41(41.0)$ \\
\hline$\geq 5$ symptoms & $412(20.8)$ & $260(19.1)$ & $43(18.9)$ & $66(25.2)$ & $38(38.0)$ \\
\hline \multicolumn{6}{|l|}{ Headache intensity } \\
\hline Low & $741(37.4)$ & $627(46.0)$ & $60(26.4)$ & $35(13.4)$ & $9(9.0)$ \\
\hline Moderate & $979(49.4)$ & $600(44.1)$ & $143(63.0)$ & $179(68.3)$ & $43(43.0)$ \\
\hline High & $183(9.2)$ & $61(4.5)$ & $22(9.7)$ & 48 (18.3) & $48(48.0)$ \\
\hline
\end{tabular}


Table 1 Overview of maternal characteristics and analgesic use in pregnancy in the total study sample and in sub-samples according to migraine pattern (Continued)

Analgesics in pregnancy

No

$1004(50.7)$

$766(56.2)$

$107(47.1)$

$90(34.4)$

28 (28.0)

Yes

977 (49.3)

596 (43.8)

120 (52.9)

$172(65.6)$

$72(72.0)$

Numbers do not add up to the total in each group due to missing values: migraine history $n=30(1.5 \%)$, maternal age $n=14(0.7 \%)$, marital status $n=27(1.4 \%)$, education $n=81(4.1 \%)$, smoking $n=64(3.2 \%)$, alcohol $n=33(1.7 \%)$, symptoms of depression/anxiety $n=6(0.3 \%)$, headache intensity $n=78(3.9 \%)$, chronic diseases $n=11(0.6 \%)$, pregnancy related diseases $n=13(0.7 \%)$

Having symptoms of depression or anxiety was defined as having a score $\geq 13$ on the ten-item self-rating Edinburgh Postnatal Depression Scale (EPDS) [18] and/ or a score $\geq 18$ on the first ten items (SCL-anxiety) of the 25-item Hopkins Symptoms Checklist (SCL-25) $[19,20]$, in either Q1 or Q2. Both instruments are widely used and validated as tools for detecting symptoms of depression and anxiety in pregnancy [21-23].

Chronic diseases recorded in the birth records include heart disease, chronic hypertension, chronic kidney disease, recurring urinary tract infections, gynecological conditions, asthma, allergy, epilepsy, rheumatoid arthritis, diabetes, genetic disorders and psychiatric disorders. These were coded as no diseases, one disease or two or more diseases. Pregnancy-related diseases include gestational diabetes, gestational hypertension, preeclampsia, eclampsia and hyperemesis, coded as no pregnancy-related diseases or one or more pregnancy-related disease(s). A variable for somatic symptoms was also created, based on a somatic symptom scale in Q2 derived from the Primary care Evaluation on Mental Disorders (PRIME-MD) [24], which included (yes/no): stomach pain, back pain, pain in arms/ legs/joints, menstrual pain or problems, pain or problems during sexual intercourse, headache, chest pain, dizziness, fainting spells, feeling your heart pound or race, shortness of breath, constipation/diarrhea/indigestion, feeling tired or having low energy, and having trouble sleeping. They were coded no somatic symptoms, 1-2 somatic symptoms, 3-4 somatic symptoms, and 5 or more somatic symptoms.

\section{Statistical analyses}

Patterns of analgesic use were analyzed descriptively for the 1981 women present at all three time points. Possible predictors for analgesic use were identified using multivariable logistic regression, with the outcome variable defined as use of analgesics at least once during pregnancy. The variables listed in Table 1 were considered as potential predictors for analgesic use. The selection of variables to be included in the potential predictor sets was based on results from previous studies, as well as the results from exploratory data analysis. Possible high inter-correlations among the independent variables were checked for, using multiple regression analysis and ensuring that the tolerance values for collinearity statistics were adequate $(>0.1)$. The covariates were fitted in multivariable logistic regression models using area under Receiver Operating Characteristics (ROC) curves and likelihood ratio tests in a backwards selection process. The analyses were restricted to complete cases. All the covariates in Table 1 were retained in the final multivariable model. Maternal age, somatic symptoms and headache intensity were used as continuous variables. The Hosmer-Lemeshow test was used to assess goodness-offit of the model, and $p>0.05$ was considered robust [25]. StataMP release 14 was used in all statistical analyses [26].

\section{Results}

Characteristics of the study sample and sub-samples

Of the total study sample of 1981 pregnant women, 100 (5.0\%) reported having migraine in pregnancy, 262 (13.2\%) had a recent history of migraine (within the past year prior to pregnancy), 227 (11.5\%) had a previous history of migraine, and $1362(68.8 \%)$ reported having no history of migraine. Characteristics of the women in the different groups are presented in Table 1. The mean age was 31.3 years (standard deviation 4.6, range 18.8-45.5 years). Age, parity, marital status, education, alcohol use, chronic diseases, and pregnancy related diseases were equally distributed across these migraine-related subgroups of women. Women with migraine were more likely to smoke and to have symptoms of depression or anxiety. They also had more somatic symptoms, higher headache intensity, and used more analgesics in pregnancy.

\section{Patterns of analgesic use}

Use of analgesics for headache or migraine was reported by a total of 977 women (49.3\%) in pregnancy, compared to 1107 (55.9\%) before pregnancy. Among women who reported migraine in pregnancy, $72.0 \%$ used analgesics during pregnancy. The patterns of analgesic use overall and of specific analgesics are shown in Fig. 3. Analgesic use declined for all groups of women, both at the beginning of pregnancy and during pregnancy. The medication groups NSAIDs, opioids, and triptans had a prominent drop in pregnancy compared to before pregnancy, and were used by less than $6.0 \%$ in pregnancy. Paracetamol constituted most of the analgesic use in pregnancy in all groups of women. It was also the most common medication before pregnancy, followed by NSAIDs, triptans (for women with 

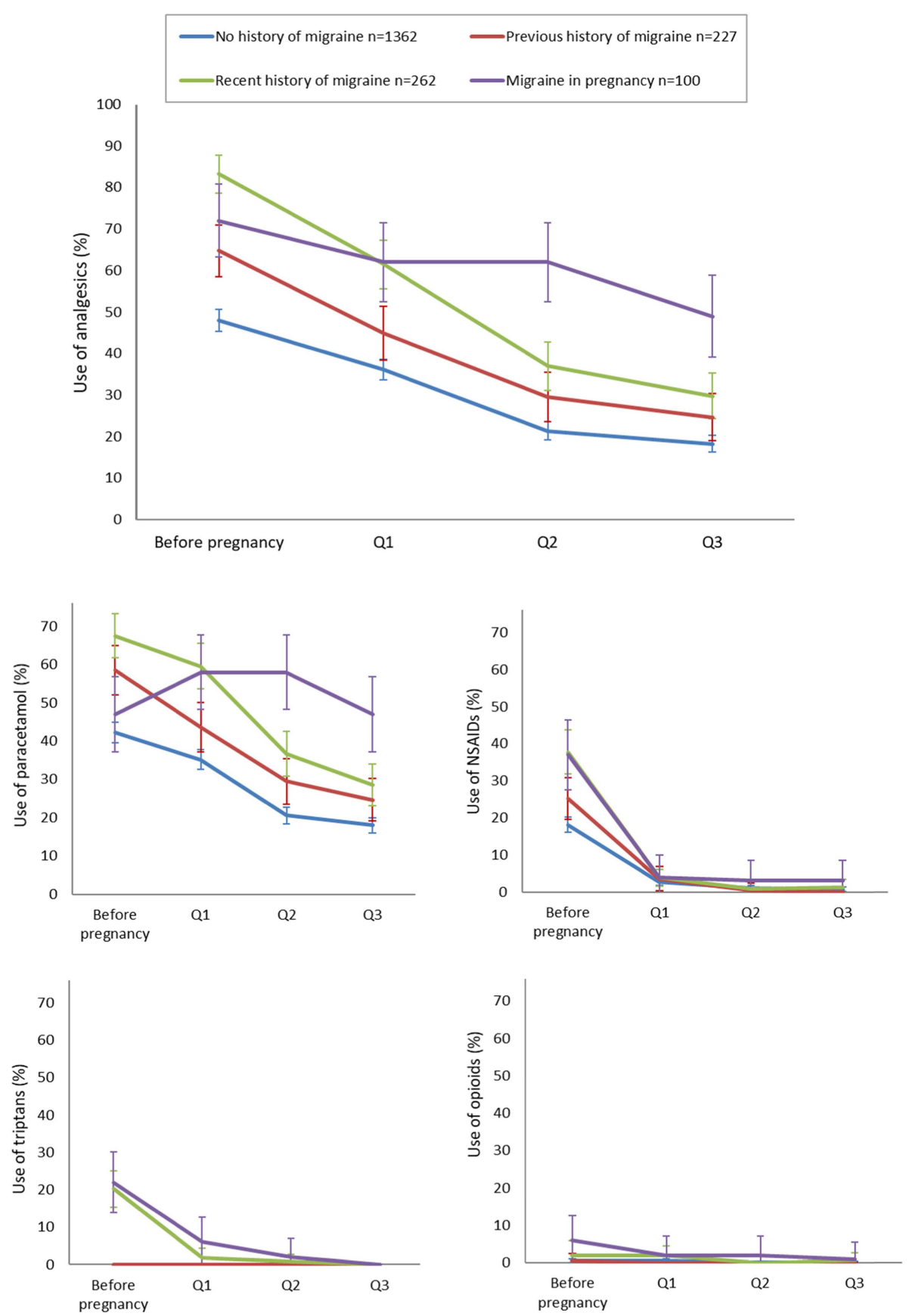

Fig. 3 Patterns of total analgesic use and use of specific analgesics before and during pregnancy among women with no migraine history, previous history of migraine, recent history of migraine (within 1 year prior to pregnancy) and migraine in the past month (\% users in each group with 95\% confidence intervals). Analgesics include paracetamol, NSAIDs, opioids and triptans, used for either migraine or headache

migraine) and opioids. Of those women using triptans and NSAIDs prior to pregnancy, $64.0 \%$ of the triptan users and $69.9 \%$ of the NSAIDs users switched to paracetamol in pregnancy (alone or in combination with other analgesics). One third of women using analgesics prior to pregnancy discontinued in pregnancy (Additional file 2: Figure S1).

Almost half of the women with migraine in pregnancy had high headache intensity (48.0\%). Of these, $18.8 \%$ did not use any analgesics, $66.7 \%$ used paracetamol alone and $14.5 \%$ used paracetamol in combination with other analgesics (Additional file 3: Figure S2).

\section{Predictors of analgesic use}

Results from the logistic regression analyses are given in Table 2. Factors positively associated with analgesic use included having a recent migraine history (Adj. OR 1.59, 
Table 2 Overview of maternal characteristics, prevalence of analgesic use and associations between maternal characteristics and analgesic use

\begin{tabular}{|c|c|c|c|c|}
\hline & \multirow{2}{*}{$\begin{array}{l}\text { Study sample } \\
n\end{array}$} & \multirow{2}{*}{$\begin{array}{l}\text { Prevalence of analgesic use } \\
n(\% \text { of } n)\end{array}$} & \multicolumn{2}{|c|}{ Associations between possible predictors and analgesic use } \\
\hline & & & Crude OR (95\% Cl) & Adjusted OR (95\% Cl) \\
\hline \multicolumn{5}{|l|}{ Maternal age at delivery } \\
\hline$<25$ & 165 & $77(46.7)$ & $1.00(0.98-1.02)$ & $0.99(0.97-1.01)$ \\
\hline $25-30$ & 588 & $304(51.7)$ & & \\
\hline $31-35$ & 768 & $385(50.1)$ & & \\
\hline$>35$ & 446 & $205(46.0)$ & & \\
\hline \multicolumn{5}{|l|}{ Parity } \\
\hline First time mother & 988 & $450(45.6)$ & 1 & 1 \\
\hline$\geq 1$ previous child & 993 & $527(53.1)$ & $1.37(1.13-1.65)$ & $1.38(1.11-1.72)$ \\
\hline \multicolumn{5}{|l|}{ Marital status } \\
\hline Married/cohabiting & 1910 & $947(49.6)$ & 1 & 1 \\
\hline Single/divorced/separated & 44 & $19(43.2)$ & $0.74(0.40-1.39)$ & $0.62(0.32-1.21)$ \\
\hline \multicolumn{5}{|l|}{ Education } \\
\hline College/university & 1294 & $609(47.1)$ & 1 & 1 \\
\hline Primary/secondary school & 606 & $332(54.8)$ & $1.27(1.04-1.56)$ & $1.07(0.85-1.35)$ \\
\hline \multicolumn{5}{|l|}{ Smoking at time of delivery } \\
\hline No & 1841 & $893(48.5)$ & 1 & 1 \\
\hline Yes & 76 & $52(68.4)$ & $2.25(1.35-3.75)$ & $1.89(1.09-3.28)$ \\
\hline \multicolumn{5}{|l|}{ Alcohol in pregnancy } \\
\hline No & 1866 & $918(49.2)$ & 1 & 1 \\
\hline Yes & 82 & $46(56.1)$ & $1.41(0.87-2.28)$ & $1.60(0.95-2.69)$ \\
\hline \multicolumn{5}{|c|}{ Symptoms of depression or anxiety in pregnancy } \\
\hline No & 1684 & $806(47.9)$ & 1 & 1 \\
\hline Yes & 291 & $170(58.4)$ & $1.41(1.07-1.84)$ & $0.86(0.63-1.18)$ \\
\hline \multicolumn{5}{|l|}{ Chronic diseases } \\
\hline None & 831 & $381(45.8)$ & 1 & 1 \\
\hline 1 disease & 747 & $368(49.3)$ & $1.10(0.89-1.35)$ & $1.08(0.86-1.35)$ \\
\hline$\geq 2$ diseases & 392 & $223(56.9)$ & $1.45(1.12-1.88)$ & $1.36(1.03-1.79)$ \\
\hline \multicolumn{5}{|l|}{ Pregnancy related diseases } \\
\hline None & 1777 & $878(49.4)$ & 1 & 1 \\
\hline$\geq 1$ disease & 191 & $93(48.7)$ & $0.91(0.66-1.24)$ & $0.86(0-62-1.21)$ \\
\hline \multicolumn{5}{|l|}{ Somatic symptoms } \\
\hline None & 182 & $59(32.4)$ & $1.15(1.10-1.20)$ & $1.08(1.03-1.14)$ \\
\hline $1-2$ symptoms & 729 & $329(45.1)$ & & \\
\hline 3-4 symptoms & 658 & $339(51.5)$ & & \\
\hline$\geq 5$ symptoms & 412 & $250(60.7)$ & & \\
\hline \multicolumn{5}{|l|}{ Headache intensity } \\
\hline Low & 741 & $257(34.7)$ & $1.42(1.33-1.50)$ & $1.33(1.25-1.43)$ \\
\hline Moderate & 979 & $593(60.6)$ & & \\
\hline High & 183 & $120(65.6)$ & & \\
\hline
\end{tabular}


Table 2 Overview of maternal characteristics, prevalence of analgesic use and associations between maternal characteristics and analgesic use (Continued)

\begin{tabular}{lllll}
\hline $\begin{array}{l}\text { Migraine pattern } \\
\text { No history }\end{array}$ & 1362 & $596(43.8)$ & 1 & 1 \\
Previous history & 227 & $120(52.9)$ & $\mathbf{1 . 3 6}(\mathbf{1 . 0 1 - 1 . 8 3 )}$ & $1.09(0.80-1.49)$ \\
Recent history prior to pregnancy & 262 & $172(65.6)$ & $\mathbf{2 . 3 3} \mathbf{( 1 . 7 4 - 3 . 1 3 )}$ & $\mathbf{1 . 5 9}(\mathbf{1 . 1 6 - 2 . 1 8 )}$ \\
Migraine in pregnancy & 100 & $72(72.0)$ & $\mathbf{3 . 3 5}(\mathbf{2 . 0 7 - 5 . 4 1 )}$ & $1.56(0.93-2.63)$
\end{tabular}

Numbers do not add up to the total due to missing values ( $<5.0 \%$ for all variables). Complete cases $n=1721$. Area under ROC curve $=0.69$. Adj. ORs are adjusted for all covariates in the table. Significant associations are marked in bold. Maternal age, somatic symptoms and headache intensity were analyzed as continuous variables. Analgesics include paracetamol, NSAIDs, opioids and triptans, used for either headache or migraine

95\% CI 1.16-2.18), headache intensity (Adj. OR 1.33, 95\% CI 1.25-1.43), smoking (Adj. OR 1.89, 95\% CI 1.09-3.28), multiparity (Adj. OR 1.38, 95\% CI 1.11-1.72), somatic symptoms (Adj. OR 1.08, 95\% CI 1.03-1.14) and having two or more chronic diseases (Adj. OR 1.36, 95\% CI 1.03-1.79). Having migraine in pregnancy and drinking alcohol in pregnancy were borderline significant.

\section{Discussion}

\section{Main findings}

Total analgesic use declined at the beginning of pregnancy and continued to decline throughout pregnancy. Analgesics that are not recommended or have limited safety documentation were drastically reduced, and paracetamol was by far the most commonly used analgesic. For the subgroup of women with active migraine, an increase in use of paracetamol was seen in pregnancy, suggesting that women on strong pain medications switched to paracetamol during pregnancy. Both migraine itself and headache intensity were associated with an increased likelihood of analgesic use, as were somatic symptoms, chronic diseases, smoking and parity.

\section{Strengths and limitations}

The ABC study had a high response rate and included women attending routine antenatal care. However, only Norwegian speaking women were included, which could limit the generalizability of the results, as other ethnic groups may have different attitudes and traditions towards medication use in pregnancy [27]. For the present study, we required women to have responded to all three questionnaires, representing only $42.9 \%$ of all study participants. A comparison of these women with the full cohort population and the general birthing population of Norway (Additional file 1: Table S1), indicate that the women in our sample, like in most questionnaire-based studies, were possibly of higher socioeconomic status. This may limit the generalizability of our findings and might have affected our results, especially prevalence and patterns of analgesic use. Associations are less likely to be affected by selection bias than prevalence estimates $[28,29]$. However, this should be taken into consideration when interpreting the results.
Both migraine and analgesic use is self-reported, and the nature of this type of study has both strengths and limitations. Self-reported medication use allows us to assess use of over-the-counter (OTC) analgesics as well as prescription analgesic use, which would not be possible using prescription registry or administrative data. However, some women might not remember or might not want to report use of medications. Previous research has found that for self-reported analgesic use, sensitivity may be low, but specificity is generally quite high [30]. Even though specific indications for use were named in the questionnaires to promote reporting, there could still be underreporting of analgesic use, particularly OTC analgesics. This would bias our effect estimates towards the null, and might lead to some factors not being identified as predictors when they should be, or underestimation of the strength of some predictors. Because we combined the categories for headache and migraine, we do not know which indication the drugs were actually used for; even in the active migraine group, drugs could have been used for non-migraine headache. This is particularity relevant for paracetamol, as it is widely used for all types of headache and is the recommended analgesic during pregnancy; therefore its use for migraine could be overestimated in our study [31].

Relying on self-reported diagnoses depends on the woman's own perception of her medical condition, which might lead to misclassification. However, the agreement between self-reported lifetime prevalence of migraine (as asked in the questionnaire), and migraine diagnosis as classified by the International Headache Society has been shown to be good, with a kappa value of 0.81 [32]. The validity of self-reported migraine has also been demonstrated in other studies [33, 34].

Finally, we were not able to do sub-analyses on specific analgesics, as very few participants used NSAIDs, opioids or triptans in pregnancy. It could be that other factors are driving use of stronger pain medication compared to paracetamol.

\section{Interpretation}

We found a marked decrease in analgesic use in pregnancy, and also throughout pregnancy. We know that 
many pregnancies are not planned, so a number of women might have been taking drugs before they discovered they were pregnant [35]. On the other hand, the first part of pregnancy is the most vulnerable period with regards to malformations, so we would expect women to be more cautious about medication use early in pregnancy [31].

The patterns were clearly different for the different medication groups. NSAIDs and triptans, which are generally not recommended, or recommended to be used with caution in pregnancy, were drastically reduced. However, despite the reduction in NSAID use, some women did persist in using NSAIDs early in pregnancy, possibly owing to their availability over the counter. The use of OTC drugs in pregnancy is common, which has been seen also for migraine patients $[15,36]$. Opioids are only recommended for limited use and have no licensed indication for migraine, which was reflected by little use both before and during pregnancy. The clear shift to paracetamol is in line with recommendations for treatment of mild to moderate migraine during pregnancy [4], although recent concerns have been raised regarding use of paracetamol in pregnancy due to possible effects on neurodevelopment [37, 38].

Migraine is often improved in pregnancy [2, 3], and many pregnant women may therefore not require migraine therapy, which could explain the decrease in analgesic use for the group with recent migraine prior to pregnancy. For women with active migraine in pregnancy, the pattern was different; overall analgesic use decreased slightly and paracetamol increased in the beginning of pregnancy. These women could also have experienced an improvement in migraine symptoms, and thereby have adequate effect from paracetamol. Another explanation could be reluctance to use stronger analgesics, and caution among physicians to prescribe drugs that are not sufficiently documented in pregnancy.

Few studies have investigated the patterns of use of headache and migraine medications in pregnancy. A Norwegian cohort study identified 3000 women with migraine before and during pregnancy and found no change in the extent or type of medications used before and during pregnancy [14]. Although not directly comparable with our study, our findings show the opposite trend, with a distinct switch to less effective, but more established drugs in pregnancy. The same trend was observed in a cross-sectional study including 400 pregnant or lactating women with migraine [16].

A considerable number of women reported high headache intensity, and many of them did not use any analgesics, while the remaining mainly used paracetamol. This suggests that there are women who are not optimally treated. This finding was also reported in another study, where less than one third of the women considered their migraine to be optimally treated [16]. For women with insufficient relief from paracetamol or with severe migraine, limited use of triptans should be considered and recognized as an alternative by prescribers. Results from studies on triptan safety in pregnancy are generally reassuring and suggest that sporadic use of sumatriptan is probably safe, although the data are limited for other triptans [4]. While it is necessary to exercise caution when using pharmacotherapy during pregnancy, untreated or inadequately managed severe migraine may seriously impact a woman's well-being, and might even pose a risk to both mother and child. In fact, several studies have suggested an association between active migraine and hypertensive diseases in pregnancy [39-42], which is a risk factor for preterm birth, low birthweight and placental abruption [43]. Moreover, the switch to less effective migraine medications such as paracetamol could impose an increased risk of analgesic induced headache [44].

We found several factors predicting analgesic use, some of them not directly related to the disease, which illustrates the need for and importance of information and advice on safe analgesic use and migraine management in pregnancy. This should be recognized by physicians as well as midwives, pharmacists, and other health care personnel communicating with pregnant women. The fact that smokers were more likely to use analgesics for headache or migraine can be due to a less restrictive attitude towards medication use in pregnancy, or addictive behavior [45]. Mothers with previous pregnancies may be less worried about using medications in their next pregnancy, if they have experienced having a healthy infant despite medication use in a previous pregnancy. Women with chronic diseases or somatic symptoms could have a lower threshold for using analgesics due to a larger total disease burden or more experience with drug treatment in pregnancy. In order to identify women at risk for suboptimal migraine treatment during pregnancy, we need more information on factors affecting drug use in pregnancy, as the literature is inconsistent.

\section{Conclusions}

Many women using analgesics for headache or migraine stop or switch to paracetamol when they become pregnant. A considerable proportion of women with migraine in pregnancy report high headache intensity, and the majority of these are not taking analgesics or just taking paracetamol. These findings are important for clinical practice, as they may contribute to a better understanding of how pregnant women handle their migraine. Counselling on safe analgesic use in pregnancy, with focus on adequate pain relief, should be endeavored for all women of childbearing age suffering from migraine or headache. 


\section{Additional files}

Additional file 1: Table S1. Comparison of maternal characteristics in the Akershus Birth Cohort (all participants and study sample) and the Medical Birth Registry of Norway (MBRN)*. (DOCX $15 \mathrm{~kb}$ )

Additional file 2: Figure S1. Analgesic use before and during pregnancy. (PDF $113 \mathrm{~kb}$ )

Additional file 3: Figure S2. Analgesic use among women with migraine in pregnancy and high headache intensity. (PDF 109 kb)

\section{Abbreviations}

ABC study: Akershus Birth Cohort Study; Ahus: Akershus University Hospital; ATC: Anatomical Therapeutic Chemical; EPDS: Edinburgh Postnata Depression Scale; MBRN: Medical Birth Registry of Norway; NSAIDs: Nonsteroidal anti-inflammatory drugs; OR: Odds ratio; OTC: Over-the-counter; PRIME-MD: Primary care Evaluation on Mental Disorders; Q1: Questionnaire 1 (gestational week 17); Q2: Questionnaire 2 (gestational week 32);

Q3: Questionnaire 3 (8 weeks after delivery); ROC: Receiver Operating Characteristics; SCL: Symptoms Checklist

\section{Acknowledgements}

The authors would like to thank the involvement of staff within the maternity wards at Ahus for their contributions towards this project. They are also grateful to all the participating women.

\section{Funding}

GMH was funded by the Norwegian ExtraFoundation for Health and Rehabilitation through the Norwegian Women's Public Health Association. The ABC study was funded by the Norwegian Research Council (project number 191098).

\section{Availability of data and materials}

The dataset analyzed during the current study is not publicly available due to data privacy restrictions and ethical restrictions established by the Norwegian Regional Committee for Ethics in Medical Research. Data are however available through application to the $A B C$ study. All enquiries about access to data should be sent to the ABC steering group, attention: Nina.Vikslokken.Odegard@ahus.no. All requests to access personal data will be handled in accordance with the procedures established by the Ethics Committee.

\section{Authors' contributions}

MEG conceived, designed and coordinated the ABC study. HN, MEG and $\mathrm{GMH}$ prepared the protocol for the current study. $\mathrm{GMH}$ analysed the data and prepared the manuscript. MW supervised the data analyses. CL contributed with buildup of the headache parts of the questionnaire and interpretation especially related to migraine. All authors were involved in interpreting the data, critically revising the manuscript and approved the final version.

\section{Ethics approval and consent to participate}

All women invited to participate in the ABC study were given written information explaining the purpose of the study and they were informed that participation was voluntary. Written informed consent was obtained from all participants. The study was approved by the Regional Committee for Ethics in Medical Research in Norway (approval number S-08013a). All data are anonymous.

\section{Consent for publication}

Not applicable.

\section{Competing interests}

The authors declare that they have no competing interests.

\section{Publisher's Note}

Springer Nature remains neutral with regard to jurisdictional claims in published maps and institutional affiliations.

\section{Author details}

Tharmacoepidemiology \& Drug Safety Research Group, School of Pharmacy, Faculty of Mathematics and Natural Sciences, University of Oslo, P.O. Box. 1068, Blindern, 0316 Oslo, Norway. ${ }^{2}$ Department of Child Health, National Institute of Public Health, Oslo, Norway. ${ }^{3}$ Health Services Research, Research Department, Akershus University Hospital and University of Oslo, Campus Ahus, Lørenskog, Norway.

Received: 26 August 2016 Accepted: 2 July 2017

Published online: 14 July 2017

\section{References}

1. Stovner LJ, Zwart JA, Hagen K, Terwindt GM, Pascual J. Epidemiology of headache in Europe. Eur J Neurol. 2006;13(4):333-45.

2. Allais G, Rolando S, De Lorenzo C, Manzoni GC, Messina P, Benedetto C, d'Onofrio F, Bonavita V, Bussone G. Migraine and pregnancy: an internet survey. Neurol Sci. 2013;34(Suppl 1):S93-9.

3. MacGregor EA. Headache in pregnancy. Neurol Clin. 2012;30(3):835-66.

4. Amundsen S, Nordeng H, Nezvalova-Henriksen K, Stovner LJ, Spigset O. Pharmacological treatment of migraine during pregnancy and breastfeeding. Nat Rev Neurol. 2015;

5. Evers S, Afra J, Frese A, Goadsby PJ, Linde M, May A, Sandor PS. EFNS guideline on the drug treatment of migraine-revised report of an EFNS task force. Eur J Neurol. 2009:16(9):968-81.

6. Nordeng $H$, Ystrom E, Einarson A. Perception of risk regarding the use of medications and other exposures during pregnancy. Eur J Clin Pharmacol. 2010;66(2):207-14

7. Twigg MJ, Lupattelli A, Nordeng H: Women's beliefs about medication use during their pregnancy: a UK perspective. Int J Clin Pharm. 2016;38:968-76.

8. Lupattelli A, Spigset O, Twigg MJ, Zagorodnikova K, Mardby AC, Moretti ME, Drozd M, Panchaud A, Hameen-Anttila K, Rieutord A, et al. Medication use in pregnancy: a cross-sectional, multinational web-based study. BMJ Open. 2014:4(2):e004365.

9. Cleary BJ, Butt H, Strawbridge JD, Gallagher PJ, Fahey T, Murphy DJ. Medication use in early pregnancy-prevalence and determinants of use in a prospective cohort of women. Pharmacoepidemiol Drug Saf. 2010;19(4): 408-17.

10. Odalovic M, Vezmar Kovacevic S, Nordeng H, llic K, Sabo A, Tasic L. Predictors of the use of medications before and during pregnancy. Int J Clin Pharm. 2013;35(3):408-16.

11. Mitchell AA, Gilboa SM, Werler MM, Kelley KE, Louik C, Hernandez-Diaz S. Medication use during pregnancy, with particular focus on prescription drugs: 1976-2008. Am J Obstet Gynecol. 2011;205(1):51. e51-58

12. Olesen $C$, Thrane $N$, Henriksen $T$, Ehrenstein $V$, Olsen J. Associations between socio-economic factors and the use of prescription medication during pregnancy. Eur J Clin Pharmacol. 2006;62(7):547-53.

13. Daw JR, Hanley GE, Greyson DL, Morgan SG. Prescription drug use during pregnancy in developed countries: a systematic review. Pharmacoepidemiol Drug Saf. 2011;20(9):895-902

14. Nezvalova-Henriksen K, Spigset O, Nordeng H. Maternal characteristics and migraine pharmacotherapy during pregnancy: cross-sectional analysis of data from a large cohort study. Cephalalgia. 2009;29(12):1267-76.

15. Källén B, Lygner PE. Delivery Outcome in Women Who Used Drugs for Migraine During Pregnancy With Special Reference to Sumatriptan. Headache 2001:41(4):351-6.

16. Amundsen S, Ovrebo TG, Amble NM, Poole AC, Nordeng H. Use of antimigraine medications and information needs during pregnancy and breastfeeding: a cross-sectional study among 401 Norwegian women. Eur J Clin Pharmacol. 2016:72(12):1525-35.

17. WHO Collaborating Centre for Drugs Statistics Methodology. ATC/DDD index 2016. http://www.whocc.no/atc_ddd_index/. Accessed 22 May 2016.

18. Cox JL, Holden JM, Sagovsky R. Detection of postnatal depression. Development of the 10-item Edinburgh Postnatal Depression Scale. $\mathrm{Br}$ Psychiatry. 1987;150:782-6.

19. Winikur A, Winikur D, Rickels K, Cox DS: Symptoms of emotional distress in a family planning service: stability over a four week period. Br J Psychiatry. 1984;144:395-9.

20. Nettelbladt P, Hansson L, Stefansson CG, Borgquist L, Nordstrom G. Test characteristics of the Hopkins Symptom Check List-25 (HSCL-25) in Sweden, using the Present State Examination (PSE-9) as a caseness criterion. Soc Psychiatry Psychiatr Epidemiol. 1993;28(3):130-3. 
21. Murray D, Cox JL: Screening for depression during pregnancy with the Edinburgh Depression Scale (EPDS). J Reprod Infant Psychol. 1990;8:99-107.

22. Eberhard-Gran M, Eskild A, Tambs K, Schei B, Opjordsmoen S. The Edinburgh Postnatal Depression Scale: validation in a Norwegian community sample. Nord J Psychiatry. 2001;55(2):113-7.

23. Sandanger I, Moum T, Ingebrigtsen G, Dalgard OS, Sorensen T, Bruusgaard D. Concordance between symptom screening and diagnostic procedure: the Hopkins Symptom Checklist-25 and the Composite International Diagnostic Interview I. Soc Psychiatry Psychiatr Epidemiol. 1998;33(7):345-54.

24. Spitzer RL, Williams JB, Kroenke K, Linzer M, de Gruy FV 3rd, Hahn SR, Brody D, Johnson JG. Utility of a new procedure for diagnosing mental disorders in primary care. The PRIME-MD 1000 study. JAMA. 1994;272(22):1749-56.

25. Hosmer DW, Lemeshow S: Assessing the Fit of the Model. In: Applied Logistic Regression. 2nd ed. Hoboken: John Wiley \& Sons, Inc:; 2000: 143-202.

26. StataCorp. Stata Statistical Software, vol. 14. College Station: StataCorp LP; 2015.

27. Baraka MA, Steurbaut S, Coomans D, Dupont AG. Ethnic differences in drug utilization pattern during pregnancy: a cross-sectional study. J Matern Fetal Neonatal Med. 2013;26(9):900-7.

28. Nilsen RM, Vollset SE, Gjessing HK, Skjaerven R, Melve KK, Schreuder P, Alsaker ER, Haug K, Daltveit AK, Magnus P. Self-selection and bias in a large prospective pregnancy cohort in Norway. Paediatr Perinat Epidemiol. 2009; 23(6):597-608

29. Nohr EA, Frydenberg M, Henriksen TB, Olsen J. Does low participation in cohort studies induce bias? Epidemiology. 2006;17(4):413-8.

30. van Gelder MM, van Rooij IA, de Walle HE, Roeleveld N, Bakker MK. Maternal recall of prescription medication use during pregnancy using a paper-based questionnaire: a validation study in the Netherlands. Drug Saf. 2013;36(1):43-54.

31. Schaefer $C$, Peters P, Miller RK. Drugs During Pregnancy and Lactation. 3rd ed. London: Academic Press; 2015.

32. Rasmussen BK, Jensen $R$, Olesen J. Questionnaire versus clinical interview in the diagnosis of headache. Headache. 1991;31(5):290-5.

33. Schürks M, Buring JE, Kurth T: Agreement of self-reported migraine with ICHD-II criteria in the Women's Health Study. Cephalalgia. 2009;29:1086-90.

34. Qiu C, Williams MA, Aurora SK, Peterlin BL, Gelaye B, Frederick IO, Enquobahrie DA. Agreement of self-reported physician diagnosis of migraine with international classification of headache disorders-II migraine diagnostic criteria in a cross-sectional study of pregnant women. BMC Womens Health. 2013;13(1):50.

35. Finer LB, Henshaw SK. Disparities in rates of unintended pregnancy in the United States, 1994 and 2001. Perspect Sex Reprod Health. 2006;38(2):90-6.

36. Werler MM, Mitchell AA, Hernandez-Diaz S, Honein MA. Use of overthe-counter medications during pregnancy. Am J Obstet Gynecol. 2005; 193(3 Pt 1):771-7.

37. Brandlistuen RE, Ystrom E, Nulman I, Koren G, Nordeng H. Prenatal paracetamol exposure and child neurodevelopment: a sibling-controlled cohort study. Int J Epidemiol. 2013;42(6):1702-13.

38. Liew Z, Ritz B, Rebordosa C, Lee PC, Olsen J. Acetaminophen use during pregnancy, behavioral problems, and hyperkinetic disorders. JAMA Pediatr. 2014;168(4):313-20.

39. Facchinetti F, Allais G, Nappi RE, D'Amico R, Marozio L, Bertozzi L, Ornati A, Benedetto C. Migraine is a risk factor for hypertensive disorders in pregnancy: a prospective cohort study. Cephalalgia. 2009;29(3):286-92.

40. Adeney KL, Williams MA, Miller RS, Frederick IO, Sorensen TK, Luthy DA. Risk of preeclampsia in relation to maternal history of migraine headaches. J Matern Fetal Neonatal Med. 2005;18(3):167-72.

41. Williams MA, Peterlin BL, Gelaye B, Enquobahrie DA, Miller RS, Aurora SK Trimester-specific blood pressure levels and hypertensive disorders among pregnant migraineurs. Headache. 2011;51(10):1468-82.

42. Bushnell CD, Jamison M, James $A H$. Migraines during pregnancy linked to stroke and vascular diseases: US population based case-control study. BM Open. 2009:338:b664.

43. Hauth JC, Ewell MG, Levine RJ, Esterlitz JR, Sibai B, Curet LB, Catalano PM, Morris CD. Pregnancy outcomes in healthy nulliparas who developed hypertension. Calcium for Preeclampsia Prevention Study Group. Obstet Gynecol. 2000;95(1):24-8.

44. Kristoffersen ES, Lundqvist C. Medication-overuse headache: a review. J Pain Res. 2014;7:367-78.

45. Ystrom E, Vollrath ME, Nordeng $\mathrm{H}$. Effects of personality on use of medications, alcohol, and cigarettes during pregnancy. Eur J Clin Pharmacol. 2012;68(5):845-51.

\section{Submit your next manuscript to BioMed Central and we will help you at every step:}

- We accept pre-submission inquiries

- Our selector tool helps you to find the most relevant journal

- We provide round the clock customer support

- Convenient online submission

- Thorough peer review

- Inclusion in PubMed and all major indexing services

- Maximum visibility for your research

Submit your manuscript at www.biomedcentral.com/submit
Biomed Central 